\title{
LUCIA MCCARTNEY \\ E A HISTÓRIA LITERÁRIA COMO DISRUPÇÃO
}

\author{
Luiz Antonio Garcia Diniz (CIAM; UQÀM - Canadá) \\ luizdiniz953@yahoo.fr
}

Ordem, ordem, o progresso nada vale, mas a ordem é necessária.

(Rubem Fonseca, Lucia McCartney)

A obra de Rubem Fonseca, Lucia McCartney, encontra-se no conjunto de publicações dos anos 70 , em uma situação de confronto bastante complexa. Confronto perante as categorias literárias consideradas canônicas e, igualmente, confronto ante as ideias sedimentadas que antecedem os anos 60 marcados pelo seu cunho conservador. Tal contexto nos levou a acionar, no interior de sua própria narrativa, as discussões sobre arte e cultura por meio de encenações literárias experimentais (o que em si já é um confronto) e, finalmente, confronto com um contexto sociocultural e político bastante tumultuado: a ditadura militar no Brasil 64/84.

Essa situação de confronto dificulta a compreensão do objeto literário pela amplificação de suas significações, visto sua complexidade, e poderia nos levar a privilegiar um dos aspectos acima citados em detrimento de sua unidade objetal inscrita em sua discursividade - ao mesmo tempo, deslizante, insidiosa e brutal - parti pris, que, evidentemente, a nosso ver, poderia conduzir a uma abordagem simplista da obra do escritor. Nosso propósito é abordar esse objeto do ponto de vista da pós-modernidade, sabendo, entretanto, das dificuldades que tal escolha nos coloca, sobretudo no que se refere às possíveis e perigosas reduções teóricas.

No livro Lucia McCartney, de Rubem Fonseca, pode-se observar, entre outros aspectos, uma oscilação do sujeito literário que transita entre o popular e o erudito, provocando uma reflexão permeada por conceitos mobilizadores, os quais remetem às questões justapostas nas reflexões sobre o canônico e o não canônico, à validade das vanguardas, à questão dos gêneros literários, à codificação da 
linguagem, etc. Para tanto, o autor recorre a uma constelação de referências a gêneros literários na estratégia discursiva utilizada pela articulação dos personagens no interior da estrutura narrativa do livro. Com esse procedimento, busca uma estruturação do objeto literário em que as contaminações formais (gêneros) se disseminam e nos deslocam continuamente de um referencial historicamente definido por um determinado tipo de narrativa a outro, o que, poderia se constituir na própria literatura que está sendo construída, a de Fonseca. Desse modo, a presença de construções imagéticas como, por exemplo, pele de alabastro, dentes de marfim, evidencia a utilização do kitch no seu sentido de forma reproduzível e esvaziada no conto "Correndo atrás de Godfrey", aspecto estrutural que, ao mesmo tempo, nos expulsa e nos atrai por meio da desmitificação irônica do cultismo barroco.

"O corpo de Joan Stimson era feito de um alabastro que filtrava a luz vermelha do seu sangue como o do altar de São Pedro: cada dente seu era uma pequena obra prima de marfim" (FONSECA, 1978, p. 152).

Tal procedimento, que remete (como citação) aos contos policiais ou roman noir, como os de Dashiel Hammet, Raymond Chandler, entre outros, é entremeado de citações "eruditas" como por exemplo, Mallarmé, no seu conto "Encontro e confronto" e Sófocles, Kafka e Pessoa em "Lúcia McCartney".

Esse tipo de elaboração arquitetônica do literário nos conduz necessariamente a refletir sobre a forma utilizada por Fonseca em seu texto. Assim, poderíamos nos interrogar e enumerar algumas questões que esse tipo de construção levanta, como por exemplo: por meio de qual forma literária a obra de Fonseca se daria a ver do ponto de vista da pós-modernidade? Primeiramente, sua relação com a chamada "morte" da história - um dos conceitos fundamentais da teoria do pós-modernismo -, transparece, por exemplo, no ponto de vista adotado, ou seja, na focalização não linear, na encenação conjunta de estilos pertencentes a uma história em construção, desmentindo, assim, a narrativa de tradição moderna. "Fim de uma narrativa" com imagem de totalidade, substituída, então, por uma história em que desponta a objetivação descontínua de momentos de uma e- 
xistência esquizofrênica e atemporal, em flagrante contraste com certa história da literatura de cunho moderno.

Um olhar historicista demandaria o recurso perspectivista elaborado por meio de uma sucessão de rupturas formais, que, por sua vez, seriam superadas pela dialética marxista ou hegeliana sob a forma de sucessivas quebras na tradição, vislumbrando uma "superação" estética que tenderia a um ideal. Ora, Fonseca, no seu construto literário, dissolve a historicidade moderna na elaboração de uma narrativa híbrida, contaminada e temporalmente conotada em fragmentos, dada sua compressão espaciotemporal, procedimento realizado pela coexistência de estilos distintos no mesmo espaço. Não há, em Lucia McCartney, a intencionalidade de romper com uma forma para dar "nascimento" a outra, a qual seria mais "depurada", ou mais próxima de um ideal a ser atingido. O que há, basicamente, é a recusa desse modus operandi, intrinsecamente moderno, pela instauração da fluidez do olhar pós-moderno.

O livro de Fonseca, além de ter sido marcado pela ditadura militar no Brasil (1969), para considerar o aspecto contextual, é elaborado por uma narrativa onde a tensão entre a comunicação e a não comunicação é bastante acentuada, daí o recurso da utilização de figuras relacionadas com as mídias informacionais: TV, filmes, discos, jornais e livros, mídias revestidas de tal ambivalência de sentidos, que de certa forma impelem a uma interrogação sobre a validade ou objetivo de seu papel ou função:

Meu tio chega diariamente por volta das sete horas, com o Estado de São Paulo debaixo do braço e diz sempre a mesma frase: 'uf, que dia, nem tive tempo de ler o jornal', sempre com a mesma inflexão e a mesma falta de significado ou destinatário. (Como o jornal, que no fim de semana é vendido a peso pela minha tia). Meu tio liga a televisão. (FONSECA, 1978, p. 39).

O "tio", assim como o "jornal", como emissores de comunicação, não se dirigem a nenhum destinatário. A ação comunicativa desencadeada pelo tio por meio da fala e a do jornal por meio da escrita ou imagem, não propõe nenhum interlocutor, como motor ou como objetivo. Os dois enunciados, o do jornal e o do tio, não encontram na situação descrita, quaisquer destinatários. Há, talvez, na redução do jornal à repetição do processo de produção e circulação de mercadorias concretizadas pela sua venda "a peso" pela tia no fim de 
semana, a inserção de uma metáfora da inutilidade da comunicação sob a forma da mensuração quantitativa entre a quantidade de informação contida no jornal e seu equivalente em peso orientado para a reciclagem econômica: a nivelação dos bens simbólicos a simples produtos vendáveis e rentáveis.

Nesse sentido, é oportuno citar João Adolfo Hansen:

O discurso não é o que diz, enfim, mas o que faz: a atenção deslocase do enunciado para as condições de possibilidade de sua produção, uma pragmática desloca a semântica, uma agonística desloca os consensos e, ainda, esta vez, na reatualização de Nietzsche via Heidegger, Platão é posto para fora da cena, entra o sofista (HANSEN, 1986, p. 51 referência).

Há, em Lucia McCartney, uma mise-en-scène, uma espetacularização da performance individual, uma luta sem trégua, em que o único Outro possível mediador é a mercadoria. O que observamos são máquinas discursivas e sexuais em contínua produção e reprodução de suas práticas, enfim, uma infinidade de dispositivos discursivos que nos fazem lembrar que a representação do sujeito moderno não cabe na sua narrativa, o que há, são simulacros movendo-se em um descontínuo temporal sempre presentificado.

O livro se inicia com um conto intitulado, não por acaso, "Desempenho", relação intercalada de amor e ódio entre o boxeador (lutador) e o público. A propósito, esses simulacros não significam, não são produtos de significados. Pertencem a uma estrutura mercadológica em que transitam como bens simbólicos de consumo e entretenimento. Como, situar então, o sujeito na obra de Fonseca, posto que a pós-modernidade e o pós-estruturalismo postulam seu desaparecimento, pelo menos nos moldes modernos? O que nos leva fatalmente a uma questão fundamental ligada às redes comunicacionais: como conciliar conceitos como intersubjetividade e significações se estes estão postos como efeitos e não como condição de preexistência da comunicação? Instaura-se, desse modo, um impasse teórico que para Foucault, segundo Hansen, constitui-se em um falso problema na medida em que a semântica integra-se nessa relação como efeito e não como causa. Não há, por consequência, um sujeito transcendental, autorreferencial, existindo previamente aos fatos, mas sim, um sujeito-função modelado por suas práticas e por elas produzido. 
Deve-se ressaltar que a noção de prática constitui-se, a nosso ver, em uma função relacionada com uma estrutura produtiva e, por consequência, o sujeito focado e resultante dessas relações será um sujeito coletivo, um construto estrutural. Esses sujeitos, caracterizados pelos efeitos de práticas - pragmáticos, móveis e relacionais desaparecerão como resultado de uma mudança epistêmica, assim como a "morte do homem" implica que sua forma-sujeito e sua função-sujeito, criados pelas artes e ciências no século XVIII, dissiparam-se - isso ocorreu na medida em que as práticas que o engendraram desapareceram - e as atuais dissolveram sua unidade produto de uma construção histórica. A lacuna aberta por uma transformação epistêmica redundando na perspectiva teórica de encontrar novas funções que caracterizariam o novo sujeito e que produziriam e revelariam o aparecimento da lacuna (HANSEN, 1986, p. 51-52).

Particularmente no conto "Encontro e confronto", temos um exemplo da falta de comunicação, ou melhor, de uma comunicação deslocada, cifrada, onde a encenação da relação sexual dos dois personagens com as prostitutas é mediada pela citação do literário. Como havia, no dizer dos personagens, uma impossibilidade da relação afetiva se concretizar na relação sexual - "pena nós não sermos homossexuais. Essas putas não sabem entender o nosso wit $^{18,}-($ FONSECA, 1978, p. 123), a relação entre os dois casais se dá mediada e sublimada pelo diálogo entremeado de referências literárias e linguísticas durante o ato sexual. É curioso ressaltar que a única divisão física entre os casais é uma divisória de vidro fosco como uma metáfora da contiguidade rompida, imagem que excita o desejo. $\mathrm{O}$ "confronto" que dá título ao conto sugere o confronto da sexualidade ambígua dos dois personagens, a limitação e divisão da sexualidade por sua organização pelas estruturas sociais, a sugestão da "passagem ao ato" psicanalítico, ou ainda, a uma falta de bordas ou limites territoriais como procedimento de definição identitária e textual.

Nos indicadores construtivos da obra, podemos ressaltar, entre outros, o aspecto narrativo marcadamente cinematográfico remetendo-nos à questão da cultura de massa, como observamos particularmente no conto "Zoom," cujo próprio título já é significativo e as passagens abaixo indicam:

18 wit: esperteza, sagacidade, inglês arcaico: conhecimento 
"Eu, para ganhar tempo; 'qual é o filme?"”. Rosa: o "Filho do Capitão Blood" (Zoom, p. 166). "Trouxemos 6 livros. Finjo que meu olho direito é de vidro, tento fazer com que o olho olhe..." (Idem, p. 163). Absolutamente mediado pelo referencial cinematográfico, voyeurista, Fonseca encena, também, a própria visão do olho substituído pela objetiva. Tento fazer com que o olho olhe... O olho é o olho da máquina, o sujeito é o sujeito-função tentando olhar pelo olho mediador de linguagens.

“Acordado a noite toda. Livro aberto em cima do peito. (Não sou maluco). As mãos fechadas, o polegar levantado. Vigiado mais de meia hora, o livro aberto em cima do peito. Olho arregalado". (p. 161).

A narrativa é construída pelo olhar que a câmera estabelece com as palavras ou frases curtas. A imagem cinematográfica sugerida corresponde a planos fechados nas frases: livro aberto, mãos fechadas, polegar levantado, olho arregalado, etc. Essa descrição de planos e de travellings, em que todo o sistema de montagem cinematográfico está em jogo, pode ser visto como um diálogo entre palavras que descrevem cenas, e cenas que solicitam o olho da objetiva para se concretizarem em linguagem. O conto de Fonseca é um roteiro ou, à la limite, seu simulacro, a encenação de um script que se revela necessária para a "cena" final, aquela da passagem de momentos de angústia para o happy end:

UF, UF! Como estou infeliz. De repente, todo arrepiado: sem estrondo o mundo fica diferente, Beatriz atrás da grade Zoom entra pelos meus olhos. Nossas mãos se agarram. Estamos tontos, o amor chega a doer, combinamos encontro no Rio, ela embarca hoje, sigo amanhã, e viveremos felizes para sempre (Zoom, p. 168).

Ressalte-se que toda a trama cinematográfica só encontra sentido na elaboração literária sob a forma de uma construção textual produtora de personagens fragmentários, cujas identidades são ou clichês citacionais do literário ou sujeitos que discutem e se comunicam por meio do literário e do cinematográfico. A recorrência ao excesso referencial produz como efeito uma intertextualidade potencialmente exacerbada, conduzindo-nos a um universo denso, multiforme e estruturado por múltiplas semioses, fenômeno observado no conjunto de textos que compõem o livro e, particularmente em "Lúcia McCartney" (talvez seja necessário salientar a importância da re- 
talhação do literário como metáfora do sistema de divisão de poderes).

Nos contos "Encontro e confronto" e "A matéria do sonho" observamos essa evidência do excesso de "matéria" literária em uma espécie de sátira à hiperinformação construída na enumeração das obras:

Queria ser filho dos dois velhinhos. Dr. R., qual o melhor livro, perguntei um dia, Crime e Castigo ou Fausta Vencida? Ele gostava mais de Crime e Castigo mas a Fausta Vencida era a sua infância. Mas também está certo de gostar mais da Fausta como você. Li: Guerra e Paz, o Príncipe e o Mendigo, o Monge de Cister, Winnetou, Pardaillan, A Vingança do Judeu, Scaramouche, Pimpinela Escarlate, Buridan, Os Três Mosqueteiros, O Homem Invisível, Drácula, Crime e Castigo, Fausta, Fausta Vencida, Eu Claudius, o Conde Belisarius, A Montanha Mágica, Os Thibault, Como Jogar Basketball, O Lobo da Estepe, Tarzan o Rei das Selvas, Os Homens de Borracha, As mulheres de Bronze, O Processo, Eurico, o Presbítero (FONSECA, A matéria do sonho, 1978, p. 136).

A afirmação do personagem ao dizer: $L i$, seguida pela vasta enumeração de livros, concretiza o próprio recurso citacional que substitui o sujeito pela prática de leitura, a leitura modelando o sujeito. O coletivo, considerando-se o aspecto que a cultura nos revela como "lugar" de existência e espacialização de múltiplos sujeitos, torna-se desse modo, na estrutura da prática um sujeito literário. Nada mais distante, portanto, das visões utópicas dos modernistas que Lucia McCartney. As perspectivas utópicas confrontam-se a cada instante na desrealização de sentidos pelo embate com o cotidiano, dando lugar a uma distópica e banalizante vida encadeada de fatos igualmente banalizantes. Talvez a recorrência ao literário sugira algo como: não há personagens nesse livro, o que há são signos linguísticos que, na ordem do discurso, são fetichizados sob a forma de mercadorias.

Há, em Fonseca, elementos bastante esclarecedores sobre a reflexão relacionada à arte de vanguarda - evidentemente confrontada com a questão do popular ou a cultura de massa - sobretudo no seu conto "Asteriscos". A rigor, porém, o livro todo é permeado por essa discussão, a das fronteiras entre ficção e crítica - lembrando que as categorias decorrentes da análise do texto, como a destruição da gramática, a recusa de comunicação e a inoperância da representação como verossimilhança são decorrentes das reflexões operadas por 
Derrida, Foucault e Deleuze -, e, desse ponto de vista, a partir do momento em que a escritura estaria submetida a uma dinâmica de transformações textuais exponencialmente ilimitáveis, o sujeito da representação, consequentemente, desapareceria, o que seria operacionalizado pela substituição ou deslocamento para o tu, redundando na constituição de um sujeito-função, submetido ou caracterizado pela função autoral produtora de leitura. (HANSEN, 1986, p. 58).

É preciso ressaltar igualmente, as características pósmodernas presentes na obra: a mise-en-scène do catálogo da lista de telefone, encenação só possível em um ato, tendo em vista a duração da obra (seis horas, pouco acessível às massas) bem como o aspecto contextual ou sua singularidade histórica, representada pelo papel do censor nesse período ou recorte. O livro de Fonseca, construído por meio de cruzamentos literários diferentes, oferece-se como uma espécie de metáfora da chamada arquitetura pós-moderna: enfatiza-se a recusa de uma relação linear do tempo pela presentificação da história como tecido complexo no construto narrativo, história em que nos são reveladas marcas ou traços da herança cultural moderna. Desse modo, não há "pureza" literária em Fonseca, sua obra é uma reflexão, enquanto metalinguagem, sobre os gêneros ou sobre os efeitos produzidos pela literatura tout court:

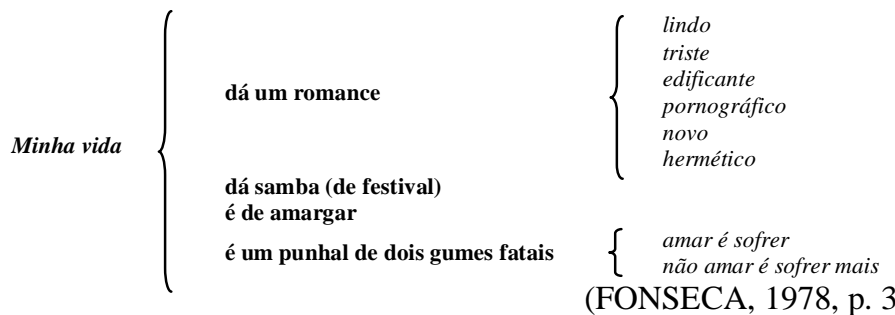

(FONSECA, 1978, p. 35)

Como essa arquitetura textual acima formalizada nos mostra, explode-se o não canônico, já que ela subverte as categorias próprias do canônico: a não sintaxe narrativa, a mistura de gêneros, sujeito sempre à deriva de limites etc. Note-se, a propósito, a hábil estratégia da inversão da flecha, deslocando o sentido habitual da relação entre causa e efeito: "a minha vida" deixa de ser o centro ou ponto de partida para diluir-se na multiplicidade dos efeitos. Na verdade, o livro é construído nessas rapsódias, nesses fragmentos descentrados, cujas temporalidades se perdem na formulação de uma nova equação es- 
paço-tempo que se caracteriza por uma compressão dessa relação, criando novas tensões produzidas no sujeito literário o que potencializa seu aspecto intertextual.

Enfim, Lúcia McCartney de Rubem Fonseca é um livro-chave para compreendermos a literatura brasileira e particularmente a literatura construída no período da ditadura. Ele nos propõe como reflexão, os traços literários do pensamento moderno, seus valores e suas formulações estéticas como a inovação e a ruptura, comentadas e questionadas no interior de sua própria estrutura narrativa. Em "Lúcia McCartney" nós temos um exemplo bastante claro da metáfora da própria concepção da escrita: montagem infinita de peças em múltiplos encaixes, como as roupas que se sobrepõem:

(O cliente tira a roupa e debaixo da camisa tem outra camisa e debaixo da calça tem outra calça e debaixo do sapato tem outro sapato. As roupas já estão batendo no teto. José Roberto continua tirando roupas do corpo com rapidez cada vez maior e dizendo importantes coisas em alemão). (FONSECA, 1978, p. 36).

É importante ressaltarmos o aspecto político mediado pela ironia e pela representação hiperbólica de siglas no conto "O quarto selo - (Fragmento) ${ }^{19}$ ", lembrando-nos de Bergman no seu filme "O sétimo selo": "E, havendo aberto o sétimo selo, fez-se silêncio no céu quase por meia hora". Já Fonseca, no "Quarto selo - Fragmento" parodia o Apocalipse segundo São João e a figura da morte sentada no seu cavalo (após a abertura do quarto selo) com a função de eliminar um quarto da humanidade, com a espada, com a peste e com a fome, remetendo-nos ao papel do Exterminador, personagem do conto, que consistia em matar altas autoridades e burocratas nunca ex-

\footnotetext{
${ }^{19}$ Quarto selo (O apocalipse segundo São João)

$\mathrm{E}$, havendo aberto o quarto selo, ouvi a voz do quarto animal, que dizia:

Vem, e vê.

E olhei,

e eis um cavalo amarelo,

e o que estava assentado sobre ele tinha por nome Morte;

e o inferno o seguia;

e foi-lhes dado poder

para matar a quarta parte da terra, com espada,

e com fome,

e com peste,

e com as feras da terra.
} 
postos em público e a salvo dos Esquadrões: "Esquadrões: grupos de especialistas em atentados pessoais com explosivos" (FONSECA, p. 44), e remetendo-nos igualmente à infinidade de siglas criadas no período em que o livro foi escrito, e que sugerem uma definição, uma territorialidade ou sistematização de funções operadas pelos dispositivos de controle:

O IPTMM tem observado uma crescente inquietação nas fuvags. É quase certo que o BBB se aproveitará disso', disse o G. G. (IPTMM: Instituto Pesquisador de Tendências Motivacionais da Massa. FUVAG: Favela Urbana Vertical de Alto Gabarito.) (FONSECA, 1978, p. 48).

Vale lembrar que o AI-5 foi imposto pelo governo Costa e Silva em dezembro de 1968 e o período correspondente à escrita do livro (governo Médici, 69-74) foi marcado pela mais dura repressão política e artística. À guisa de finalização e para "finalizar" este trabalho, é necessário explicitar, grosso modo, que os elementos teóricos que estão em jogo e sempre presentes nas reflexões sobre as relações entre pós-modernidade e cultura estão intrinsecamente ligados a interrogações como as que seguem: as práticas culturais contemporâneas são transformações teleológicas com origem no fluxo histórico organizadas por superações contínuas apontando para um futuro radiante? Ou se, ao contrário, essas mesmas práticas, não pretendem e não objetivam quaisquer finalidades, a não ser a própria performance ("Desempenho", FONSECA, p. 9) da singularidade escritural independentemente da significação histórica? e, por esse viés, poderíamos dizer que tais práticas se caracterizariam pelo fato de serem vividas como momentos de singularidades irrepetíveis e nunca no interior de uma pretensa totalização da experiência cultural.

Se optarmos pela segunda abordagem, como no nosso caso, o livro de Rubem Fonseca pode ser considerado, como uma grande encenação literária da capacidade performática da máquina escritural, em que o sujeito literário é investido de funções estruturais decorrentes de uma prática e constituindo-se nela como resultado e consequência discursiva.

- Ordem, ordem! Uma página em branco - interpretatio cessat in claris. Ordem (FONSECA, p.165). 


\section{REFERÊNCIAS BIBLIOGRÁFICAS}

ADORNO, T. W. O fetichismo na música e a regressão na audição. In: Textos escolhidos - Os pensadores. São Paulo: Abril, 1978, p. 165-191. tes, 1988.

Teoria estética. Lisboa/ São Paulo: Edições 70/Martins Fon. Estrutura da notícia. In: Crítica e verdade. São Paulo: Perspectiva, 1978, p. 57-67. . Mitologias. 7. ed. São Paulo: Difel, 1987.

; HORKHEIMER, M. A indústria cultural: o esclarecimento como mistificação das massas. In: Dialética do esclarecimento. Rio de Janeiro: Zahar, 1985, p. 113-156.

BENJAMIN, Walter. A obra de arte na época de suas técnicas de reprodução. In: Textos escolhidos - Os pensadores. São Paulo: Abril, 1978, p. 05-28.

. Experiência e pobreza. In: Obras Escolhidas II: Magia e técnica, arte e política. São Paulo: Brasiliense, 1989.

BROCH, Hermann. Kitsch y arte de tendência. In: DORFLES, Gillo (Org,) et alii. El kitsch - Antología del mal gusto. Barcelona: Lumen, 1973.

BÜRGUER, Peter. O significado da vanguarda para a estética contemporânea: resposta a Jürgen Habermas. Arte em revista, São Paulo: CEAC, 7, p. 91-92, ago./1983.

CHKLOVSKI, V. Arte como procedimento. In: EIKHEMBAUM, B. Teoria da literatura - Formalistas Russos. 2. ed. Porto Alegre: Globo, 1976, p. 39-60.

CONNOR, Steven. Cultura pós-moderna - introdução às teorias do contemporâneo. 2. ed. São Paulo: Loyola, 1993.

DORFLES, Gillo. Kitsch e cultura - para uma fenomenologia do mau gosto. In: Novos ritos, novos mitos. São Paulo: Perspectiva, 1979. 
. Kitsch e cultura. Aut-Aut - Rivista di Filosofia e di Cultura, Milano: Lampugnani Nigri Editore, 73, p. 53-62, 1969.

. Valores ideológicos y lúdicos de la cultura de masas/ "kitsch" y cultura. In: Nuevos ritos, nuevos mitos. Barcelona: Lumen, 1969.

EAGLETON, Terry. Capitalismo, modernismo e pós-modernismo. Crítica marxista, São Paulo: Brasiliense, 2, p. 53-68, 1995.

ECO, Umberto. Apocalípticos e integrados. São Paulo: Perspectiva, 1970.

. O super-homem de massa. São Paulo: Perspectiva, 1991.

ENZENSBERGER, Hans Magnus. As aporias da vanguarda. Revista Tempo Brasileiro, Rio de Janeiro: Tempo Brasileiro, 26-27, p. 85112, jan - mar/1971.

FONSECA, Rubem. Buffo \& Spallanzani. São Paulo: Cia. das Letras, 1992.

. Lúcia McCartney. Rio de Janeiro: Codecri, 1978.

GREENBERG, Clement. Vanguarda e kitsch. In: ROSEMBERG, Bernard \& WHITE, David Manning. Cultura de massa. São Paulo: Cultrix, s/d, p. 121-134.

. Notas sobre el problema del kitsch. In: DORFLES, Gillo (Org,) et alii. El kitsch - Antología del mal gusto. Barcelona: Lumen, 1973, p. 49-67.

. Crisi della nostra cultura. Aut-Aut - Rivista di Filosofia e di Cultura, Milano: Lampugnani Nigri, 19, p. 03-20, 1954.

HABERMAS, Jürgen. Modernidade versus pós-modernidade. Arte em Revista. São Paulo: CEAC, 7, p. 86-91, ago/1983.

HANSEN, João Adolfo. Alegoria - construção e interpretação da metáfora. São Paulo: Atual, 1986.

. Pós-moderno \& cultura. In: CHALHUB, Samira (Org.) et alii. Pós-moderno \&. Rio de Janeiro: Imago, 1994, p. 37-84.

HARVEY, David. Condição pós-moderna - Uma pesquisa sobre as origens da mudança cultural. 4. ed. São Paulo: Loyola, 1994. 
HUTCHEON, Linda. Ironie, satire, parodie. Poétique, Paris: Seuil, 46, p. 140-155, avr./1981.

. Poética do pós-modernismo - Teoria, história, ficção. Rio de Janeiro: Imago, 1991.

. Uma teoria da paródia. Lisboa: Edições 70, 1989.

JAMESON, Fredric. Pós-modernismo - A lógica cultural do capitalismo tardio. São Paulo: Ática, 1997.

JENNY, Laurent et alii. (Orgs.). Intertextualidades. Coimbra: Almedina, 1979.

MCCDONALD, Dwight. Masscult and midcult. The Partisan Review, New York: Ramdom House, 2, p. 203-233 e 4, p. 589-631, 1960.

. A crise do passado - modernidade, vanguarda, metamodernidade. São Paulo: Experimento, 1994.

. A crise do passado - modernidade, vanguarda, metamodernidade. São Paulo: Experimento, 1994.

MERQUIOR, José Guilherme. Kitsch e antikitsch. In: Formalismo e tradição moderna - o problema da arte na crise da cultura. São Paulo: Forense, 1974, p. 07-48.

MOLES, Abraham. O kitsch - arte da felicidade. 2. ed. São Paulo: Perspectiva, 1975.

MORICONI, Ítalo. A provocação pós-moderna. Rio de Janeiro: Diadorim, 1994.

MORIN, Edgar. Cultura de massas no século XX - $O$ espírito do tempo. 2 ed. São Paulo: Forense, 1969, 2 vols.

PAZ, Octavio. Invenção, subdesenvolvimento, modernidade. In: Signos em rotação. São Paulo: Perspectiva, 1972, p. 133-137.

. Os filhos do barro. Rio de Janeiro: Nova Fronteira, 1984. (Capítulos I, II, VI).

ROSEMBERG, Harold. Cultura pop: a crítica kitsch. In: A tradição do novo. São Paulo: Perspectiva, 1974, p. 191-198. 


\section{FACULDADE de FoRMAÇÃO de PROFESSORES}

ROUANET, Sérgio Paulo. Do pós-moderno ao neomoderno. Revista Tempo Brasileiro, Rio de Janeiro: Tempo Brasileiro, 84, p. 86-97, jan.-mar./1989.

SANTOS, Lídia do Valle. Kitsch e cultura de massa na América Latina: a narrativa latino-americana nos anos 70-80. Tese de doutorado apresentada à FFLCH/USP, São Paulo, 1993.

SONTAG, Susan. Notas sobre camp. In: Contra a interpretação. Porto Alegre: L\&PM, 1987, p. 318-337.

SUBIRATS, Eduardo. Da vanguarda ao pós-moderno. 3. ed. São Paulo: Nobel, 1987.

XAVIER, Ismail. Alegoria, modernidade, nacionalismo. Revista Novos Rumos, São Paulo: Novos Rumos/ Instituto Astrojildo Pereira, 16, 51-71, 1990. 